\title{
Antibody Binding Site
}

National Cancer Institute

\section{Source}

National Cancer Institute. Antibody Binding Site. NCI Thesaurus. Code C13193.

The site at which an antibody makes direct physical contact with a corresponding epitope on an antigen. 